\title{
Prepositional Phrases in Modern Standard Arabic: An Agree-Based Analysis
}

\author{
Ahmad Ismail Assiri \\ Faculty of Languages and Translation, King Khalid University, Abha, Saudi Arabia
}

\begin{abstract}
Prepositions, in Arabic traditional grammar literature, have been analyzed as Genitive Case assigners (Hasan, 1976; Sibaweihi, n.d.). This paper presents a phase-based analysis for prepositions (Ps) in Modern Standard Arabic (MSA). The analysis is built on Chomsky's (2005, 2008) Feature-Inheritance model of Agree. In this proposed analysis, Prepositional Phrases (PPs) in MSA are analyzed as phases, where a Probe-Goal relation is established between the prepositional Probe $p$-P and the DP in its searching domain (i.e., its complement). The outcome of this relation is valuation of the unvalued Case feature on this DP complement (i.e., Genitive Case), and a similar valuation to the unvalued phi-features ( $\varphi$-fs) on the Probe $p$-P.
\end{abstract}

Index Terms - agree, feature-inheritance, Arabic, preposition

\section{INTRODUCTION}

Arabic prepositions (Ps) such as ila, fi, min, bi-, and $l i$ in the following examples are Case assigners which assign Genitive Cases to their complement Determiner Phrases (DPs), as can be seen from the morphological realization on each of these complements:
(1) ðahaba went Ali-Nom to ila as-suuq- $i$ 'Ali went to the market'
(2) yuzadu kitaab-un fi al-haqiibat- $i$ (There) Exists book-Nom in Def-bag-Gen 'There is a book in the bag' Came Ali-Nom from Def-school-Gen
'Ali came from the school'
(3) zaa?a Ali-un $\min$ al-madrasat- $i$
(4) marartu bi- ar-rajul-ayn Passed(1s)by Def-man-(dual/Gen) 'I passed by the two men'
(5) PaSțaytu $\quad l i$ - Ahmad- $a$ ar-risalat-a gave(1s) to Ahmad-Gen Def-letter-Acc 'I gave the letter to Ahmad'

The morphological realization of the Genitive Case varies depending on the type of the DP complement. That is, $-i$ is the default form for the Genitive Case morpheme. The morpheme -ayn is used with dual nouns as in rajul-ayn (dual form of 'man'), while - $a$ is used with the name Ahmad, which is diptote (Hasan, 1976; Sibaweihi, n.d.).

When the complement of a $\mathrm{P}$ is followed by a modifying adjective, the Genitive Case morpheme $-i$ appears on that adjective as well:
(6) Pakala
Ali-un
min aț-ṭaaam-ial-laðeeð- $i$
$\operatorname{Ate}(3 \mathrm{~m})$
Ali-Nom from Def-food-Gen
Def-delicious-Gen
'Ali ate from the delicious food'

Note that Arabic adjectives (generally) show agreement with their modifying nouns in Number, Gender, and Case. The adjective al-laðeeð- $i$ 'Def-delicious' in (6) agrees with at-țaSaam- $i$ 'food' in Case (Genitive), and the only possible source for this Case is the preposition min 'from'.

Section II presents a comparison between Arabic and English Prepositional Phrases (PPs) in terms of form, function, usage, meaning, and syntactic function. An overview of some analyses of PPs will be presented in section III. The proposed analysis will be presented in section IV, followed by some concluding remarks in section V.

\section{Overview of ENGLiSH AND Arabic Prepositional PHRASES}

PPs have been classified based on their function, form, and usage. Ps across languages function as connectors of one word in the sentence to another. Specifically, Ps usually connect their complements to other parts in the sentence, such as nouns, verbs, or adjectives (Quirk, Greenbaum, Leech, \& Svartvik, 1985; Van Valin, 2004; Wishon \& Burks, 1980):

(7) There is a book in the bag. 
(8) Linda is fond of chocolate.

(9) The boy ran to the gate.

Ps in, of, and to in English connect their complements to the noun 'a book' in (7), the adjective 'fond' in (8), and the verb 'ran' in (9), respectively.

Like English and many other languages, Arabic Ps connect their complements to other words in the sentence. For instance, ila 'to' in example (1) connects the complement suuq-i 'market-Gen' to the verb Jahaba to reveal the relationship between the two elements; similarly, $f i$ 'in' connects its complement al-haqiibat-i 'the bag' to the noun kitab in example (2) above.

In terms of form, Ps in English are classified into two types: single (e.g., in, on, etc.), and complex (i.e., made up of more than one P: in spite of, in front of, etc.). Carter \& McCarthy (2006) list more than 50 Ps of this type in English. The complex class is formed of two- or three-word sequences (see, Quirk et al., 1985, for detailed explanation). The complex class is said to be open in the sense that new combinations can be formed (Macková, 2012).

The number of Ps in Arabic ranges between 17 and 21 (Alhawary, 2016; Saeed, 2014). Ps in Arabic show some similarities with their corresponding Ps in English; that is, like English, Ps in Arabic have been classified into different categories depending on their function, form, and usage. Such classification is not essential to the proposed analysis; however, a short review of the nature of Ps in Arabic is due.

In terms of form, Hamdallah and Tushyeh (1993), and Saleh (2015) state that Arabic Ps are morphologically independent (separable), and independent (inseparable). For example, min, ila, etc. (see, examples (1) - (3), above) are separable Ps, while $b i$ - and $l i$ - in (4) - (5) are always attached to their complements.

Based on their function (and form), Saeed (2014), and Saleh (2015) (among others) add a third type of Ps in Arabic: Semi-prepositions (i.e., xalf 'behind', qabl 'before', basd 'after'). According to them, this type of Ps not only function as mere Ps, but also as nouns and adverbs:

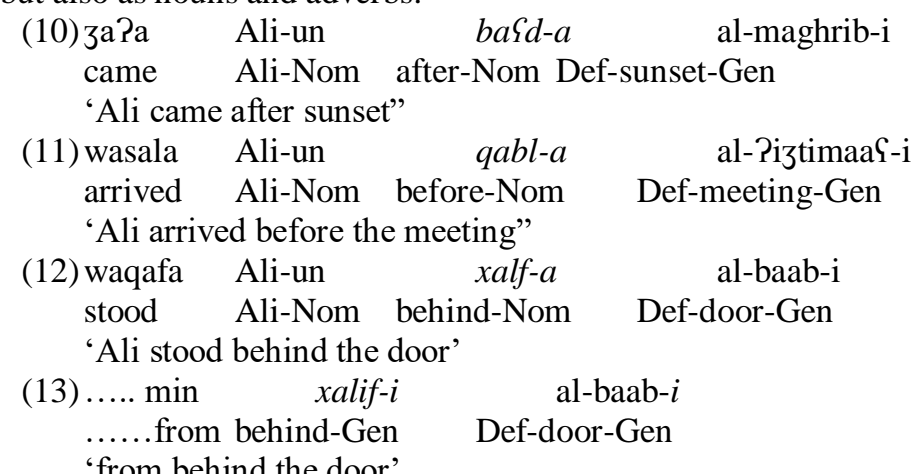

Note, however, that $b a q d$, qabl, and xalf inflect for Case (i.e. Nominative (-a) and Genitive $-i$ in (13)), and thus resemble nouns and adjectives which inflect for Case. Saeed (2014) argues that Arabic semi-prepositions resemble English in that they can form combinations with real (independent) Ps in Arabic, thus creating complex forms as shown in (13).

Ps vary in terms of their usages. For instance, Quirk et al. (1985) classify the usages of PPs in English as: (a) Ps that indicate time (i.e., temporal) or spatial (i.e., Ps of location, and direction) relationships, (b) Ps which indicate cause or purpose, (c) Ps which indicate means or agentive, and (d) Ps which indicate accompaniment, concession, respect, support, and /or opposition.

Like English, Arabic Ps are used to denote temporal and spatial relationships. They are also used to express notions of resemblance, cause, accompaniment, and exception (see, Al-Marrani, 2009, for more on the uses of Arabic Ps).

Hasan (1976) argues that Ps in Arabic do not carry meanings themselves, but they carry meanings in other element (i.e., their meanings are dependent on the elements with which they occur). However, Saleh (2015) states that Ps come in different meanings whether they are attached to nouns or not. Notice how the meaning of the verb rayib-tu 'wanted-I' in (14) and (15) changes when the P changes:

$$
\begin{aligned}
& \text { (14) rayib-tu fi liqaa?ika } \\
& \text { wanted-I to meeting-you } \\
& \text { 'I wanted to meet you' }
\end{aligned}
$$

(15) rayib-tu San liqaa?ika

'I ignored meeting you/ not interested in meeting you.'

The change in meaning indicates that it is the $\mathrm{P}$ which identifies the meaning of the sentence. Thus, Ps do carry meanings themselves.

Structure of PPs

PPs are mandatorily made of a $\mathrm{P}$ and a complement. This way, PPs are different from other syntactic phrases where a single word can make up a phrase (Downing \& Locke, 2006). Based on their position in the structure, PPs can have either adjectival or adverbial Function (Frank, 1972). That is, a PP can function as an adjectival phrase when it follows and describes a noun or an adjective, as in (16) and (17), respectively: 
(16) The boy with the blue shirt.

(17) John is very good at math.

The PP 'with the blue shirt' describes the noun 'the boy', while PP 'at math' modifies the adjective 'good'. Moreover, a PP can also function as an adverbial phrase as in (18) where PP 'in the morning' modifies the adverb 'early':

(18) We should get up early in the morning.

B. Preposition Stranding and Pied-Piping

PPs in English as well as in Arabic can be pied-piped. This way PPs appear at the beginning of the sentence as shown in the following examples:

(19) About what are you talking?

(20) tatahadaӨuun San maða?

talking(3mp) about what?

'What are you talking about?'

The PP San maða 'about what' in (20) can be pied-piped to the beginning of the structure in Arabic, as shown in (21):

(21) San maða tataћadaӨuun?

about what talking( $3 \mathrm{mp})$

'About what are you talking?'

Ps are usually placed before their complements; however, in English, it is possible for a P to get stranded, as in the following examples:

(22) What are you talking about? (Open interrogatives)

(23) This is the book I told you about (Relative Clauses)

(24) This bed has been slept in. (Passive construction)

Unlike English, Ps in Arabic cannot be stranded ${ }^{1}$, as the ungrammaticality of (25) shows:

(25) *maða tataћadaӨuuna San?

What talking(3mp) about?

Having briefly introduced the forms, functions, and usages of Ps in Arabic and in English, the next section will overview some of the analyses proposed for PPs.

\section{ANALySES FOR PREPOSITIONAL PHRASES}

Different analyses have been proposed for Ps. Some of these analyses have discussed the meanings of Ps, their syntactic structures (i.e., the kind of complements Ps take, the premodifiers which can appear with Ps) (e.g., Carnie, 2008), and the use of Ps as postmodifiers (e.g., Biber, Johansson, Leech, Conrad, \& Finegan, 1999). Other studies have analyzed Ps as functional elements (e.g., Baker, 2003, for English Ps), and lexical (e.g., Jackendoff, 1977; O'Grady, 1996), while others have proposed that Ps form a hybrid category which combines properties from both categories ${ }^{2}$ (Chanturidze, Carrolla, \& Ruigendijk, 2019; Tseng, 2000). In terms of their syntactic function, different analyses have considered Ps as predicative (e.g., Stowell, 1983), non-arguments (e.g., Baker, 2003), adjunct modifiers, etc.

The following paragraphs, however, will limit the discussion of Ps to their syntactic, internal structure due to the limited scope of this paper.

Baker (2003) analyzes Ps as functional categories, and states that "whether an item takes a specifier or not is thus an important characterizing feature for the functional categories" (p. 25). That is, lexical verbs acquire their specifiers by External Merge, while functional tenses and complementizers (including Ps) acquire their specifiers through movement (Internal merge).

Baker reasons for this conclusion through typological facts from different languages (i.e., the limited number of Ps). Baker also follows researchers such as Croft (1991), Grimshaw (1991), among others, who consider Ps to be closely related to case markers, thus functional (i.e., functional category K proposed by Lamontagne \& Travis (1987) and Bittner \& Hale (1996)). Furthermore, Baker based his classification of Ps on the fact that there are no derivational processes that involve Ps in English, for instance, and in many other languages ${ }^{3}$ as well.

Tseng (2000) states that Ps can be lexical or functional based on their uses. Tseng explains that functional Ps are sometimes referred to as "case-marking" or "non-predicative", as in (26):

(26) John gave a book to Mary.

Notice, however, that $\mathrm{P}$ to in (27) is lexical:

(27) Mary went to school.

\footnotetext{
${ }^{1}$ Notice however that p-stranding becomes possible in MSA, and in many other dialects of Arabic (see, e.g., Algryani, 2019, for Libyan Arabic), but two conditions must be met: a. A resumptive pronoun must cliticize onto the preposition, and b. A complementizer is used as in this example: man allathi jaa?a maSa-ka? who that came with-you 'who came with you?'

${ }^{2}$ Keizer (2008), for instance, concludes that all English Ps are lexical except of and by which show functional properties when associated with deverbal nouns as in: 'The treatment of the patient by the doctor' (p. 248).

${ }^{3}$ Baker adds if Ps are functional then other functional categories such as D (e.g., pronouns) can incorporate into P that governs them. Note that this is the case in Arabic: min- $h u$ 'from-him', min- $k a$ 'from-you', etc.
} 
Tseng further argues that functional Ps show "high fixedness" (p. 28), while lexical Ps show low fixedness. Still, however, there are Ps which show intermediate level of fixedness. High fixedness entails that replacing a $\mathrm{P}$ in a given context with another $\mathrm{P}$ turns this context into ungrammatical as in (28):

(28) *Delicate negotiations resulted at/for/on/to/with/by an acceptable compromise. (p. 28)

Ps with lower degree of fixedness make replacement of such Ps possible, as can be seen in (29):

(29) The magician put the rabbit on/behind/under/beside his top hat. (p. 28)

According to Tseng, functional Ps are fixed by an element external to the PP. For clarification, the verb resulted in (30) is the fixing trigger.

(30) The negotiations resulted in ...... .

To demonstrate this, Tseng (p. 30) states that "[a] particular structural relationship must exist between an external fixing trigger and the preposition it fixes. In particular, the PP headed by the fixed preposition P must be a complement of the trigger $\mathrm{X}^{\prime \prime}$ in $(31)$ :

(31)

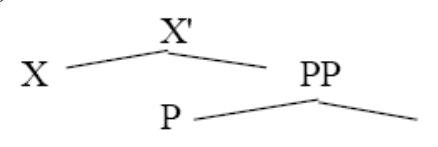

Tseng adds that fixing triggers can be internal (i.e., fixed by their complements):

(32) Those people are in the know. (p. 31)

In this example, the only possible $\mathrm{P}$ is in. However, if we take out the complement 'the know', it becomes possible for any $\mathrm{P}$ to fill in the same position:

(33) Those people are [ $\left.\mathrm{P}_{\ldots}{ }_{2}\right]$ [NP _ _ _ ] $]$

Thus, it is the complement of in which is the fixing trigger for this $\mathrm{P}$ in this example, not the NP subject or the verb ${ }^{4}$. Tseng concludes that, as far as syntactic properties are concerned, both lexical and functional ${ }^{5}$ Ps show no difference between them (i.e., both show the same projection properties) (p. 79).

Researchers such as den Dikken (2010) and Svenonius (2010) follow cartographic approaches to the analysis of Ps. These approaches are based on Jackendoff's (1990) analysis of PPs, which argues for two basic semantic components: Path and Place. Specifically, in den Dikken's analysis, Ps are lexical categories which project a functional structure with various functional heads (i.e., $\mathrm{P}_{\mathrm{LOC}}$ and $\mathrm{P}_{\mathrm{DIR}}$ are lexical categories).

Like den Dikken, Svenonius (2010) argues for a locative $\mathrm{P}$ that is syntactically composed of different smaller functional projections, but these researchers differ on the number and interpretation of these functional projections. That is, Svenonius proposes four classes of Ps: projective, bounded, extended, and particles, where locative Ps are projective and bounded, while path or directional $\mathrm{P}$ are extended. Particles, on the other hand, form an independent class which conforms to neither class.

Rooryck (1996) argues that PPs are formed by a lexical head P and a functional head F. This F head is responsible for case assigning of PPs. According to Rooryck, the functional projection for PP can have weak and strong features which allow incorporation of $\mathrm{P}$ into $\mathrm{F}$.

Puigdollers (2013) proposes a simplified version of the "cartographic approach" (p. 68). Following Svenonius (2010), Puigdollers argues that locative and directional PPs contain a small (functional) $p$ head in PPs (like little $v$ in $v \mathrm{P}$ ). This $p$ functions like $v$ in that it is the locus of case licensing, and it introduces the external argument of PP. Thus, Puigdollers considers $p($ ath $)$ and $p$ (lace) as functional heads, which are also the locus of $\varphi$-features in the sense of Chomsky (2008) (i.e., phasal heads). Conversely, the other heads of $\mathrm{p}($ ath) and $\mathrm{P}(\mathrm{lace})$ are analyzed as non-functional heads. Puigdollers then proposes the following structure of path and place Ps (p. 70):

(34)

P of direction

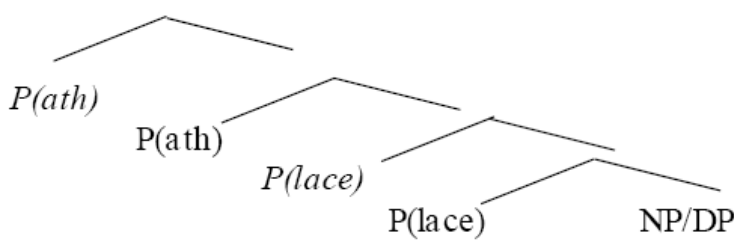

P of location

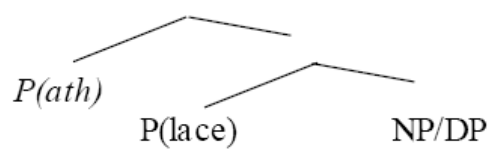

\footnotetext{
${ }^{4}$ Based on Tseng's analysis, the verb rayiba in example (14) and (15) above is the fixing trigger.

${ }^{5}$ Note, however, that Rauh (2002) argues for a non-head analysis for functional Ps, and concludes that they are NPs syntactically, for they have limited projection properties, they do not allow specifiers or modifiers, and they exhibit one complementation pattern: [ assign case, and express relational content. NP]. In addition, they
} 
Note that this can be headed further by a $v \mathrm{P}$ which takes Path as its complement.

Puigdollers argues, in the sense of Richards (2011), that a phasal domain constitutes phasal and non-phasal elements. According to Puigdollers, $p$ (ath) and $\mathrm{P}$ (lace) are phasal heads which bear unvalued set of $\varphi$-features and as such probe for DPs which can value these unvalued features. When agreement occurs, $p$ (ath) results in valuing Accusative Case features on the DP, while $p$ (lace) values Dative Case. Puigdollers adds that certain phasal heads may be defective (i.e., bear an incomplete set of $\varphi$-features). When defective, the phase head belongs to the "immediately next strong phase, that is, $v^{\prime \prime}($ p. 88).

As far as referential index and the ability to take specifiers, Baker (2003) argues that PPs are similar to APs in that they do not have referential index or specifiers (p. 311). Conversely, Jackendoff (1977) argues that Ps are referential, and a P can have a subject (within its projection). That is, the syntactic structure of PPs can be analyzed as X'-heads, and as such a P can combine with its complement thus forming P', which in turn can combine (optionally) with a specifier and a maximal projection of PP is formed. Baker adds that PPs in English are not arguments, for "English PPs cannot normally appear in subject positions, object positions, or as the objects of a preposition"6.

Some PPs in Stowell's (1983) analysis are predicates which theta-mark a subject in copular sentences as in (35), and in small clause constructions as in (36):

(35) Chris $_{\mathrm{i}}$ is $\left[\mathrm{t}_{\mathrm{i}}\right.$ in the kitchen].

(36) I want [a table in the kitchen].

(37) Chris put the book in the box.

Note that other analyses posit that the theme the book in (37) is not the direct object of 'put', but it is the subject of the PP (e.g., Hoekstra, 1988, den Dikken, 1995).

Similar analyses of PPs have argued that Ps function as predicates, based on the unique relation between the P and their complements ${ }^{7}$ (see, e.g., Ouhalla, 1994; and Van Valin, 2004). As such, Ps can assign case to their complements (just like verbs). Similarly, researchers Halliday \& Matthiessen (2014), in their classification of words in a functional grammar of English, have included Ps to the verbal class based on Ps nature of predication. Moreover, Hale \& Keyser (1993) argue that Ps form predicates, and as such, they require subjects. According to these researchers, subjects are located outside the PP projection.

The following section presents the proposed analysis for Arabic PPs. In this section, PPs are analyzed as phases, and as such a Probe-Goal relation will be initiated between Ps and their complement DPs, thus allowing the derivation to converge.

\section{THE PROPOSAL}

This section lays out an Agree-based analysis for PPs in Modern Standard Arabic (MSA). It has been shown that Ps in Arabic can assign Genitive Cases to their DP complements. In this proposed analysis, it will be assumed, following den Dikken (2010), that prepositional case is functional (i.e., it is assigned or checked in a specific functional head). Particularly, Chomsky's (2005, 2008) Feature-Inheritance (FI) model of Agree will be adopted. It will also be proposed, following Chanturidze, et al (2019), Puigdollers (2013), and Svenonius (2010), that PPs contain a small $p$ head parallel to little $\mathrm{v}$ in the PP domain. This little $p$ resembles $v$ in that it is the locus of case licensing, and it introduces the external argument of the PP.

The proposed analysis shows that PPs in Arabic are phasal ${ }^{8}$, and under Agree model, they must enter into agree relation with another element in the structure. Specifically, it shows that this $p$ head bears a set of unvalued features (i.e., $\varphi$-features), which must be valued for the derivation to converge, in addition to a valued [CASE] feature with Genitive value. Following the FI model of Agree, it will be argued that the functional/ phasal head transfers its features to a proxy head (i.e., lexical P) with which it should form a $p$-P Probe ${ }^{9}$. This probe must value its unvalued features against a Goal which bears valued set of $\varphi$-features, and an unvalued CASE feature (i.e., DP). Consider the proposed structure for PPs (38):

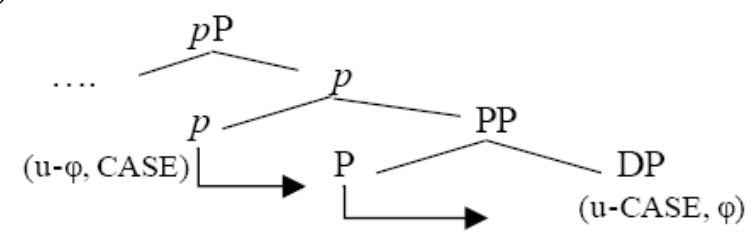

\footnotetext{
${ }^{6}$ Note, that Zewi (2012) argues that PPs in Semitic languages can be subjects, as in the following example from the Holy Qur'an (2:10):

a. wa la-hum Saðab-un Paliim (p. 468)

And for-them punishment painful

'Literally: for them is painful punishment.'

${ }^{7}$ For a list of complements Ps can take, see Downing and Locke (2006).

${ }^{8}$ See, Radford's (2004) discussion on the assumption that PPs in English can be phases.

${ }^{9}$ Kayne (2005) argues that Ps can probe for Goals.
} 
In this structure, the $p$-P Probe finds DP (in P's complement) and Agree occurs: The unvalued set of $\varphi$-features on $p$ $P$ receives valuation and at the same time, the unvalued Case on DP gets valued, thus resulting in Genitive value on DP. In this sense, phasal $p$ Ps resemble phasal $v$ Ps in that they transfer their unvalued features to proxy heads (i.e., lexical V), and after $v$-V probe is formed, the search continues for potential Goals which can value this probe's unvalued features.

The analogy between $v \mathrm{Ps}$ and $p \mathrm{Ps}$ can be extended. Specifically, it can be assumed that phasal $p \mathrm{P}$ can have an external DP (in its specifier position) (cf. Brattico, 2012, for a similar conclusion that PPs can have specifiers). This specifier position can host the object walad-an 'boy-Acc' of a V as shown in representation (40) for example (39):
(39) raPa
Ali-un
walad-an $f$
saw(3ps) Ali-Nom boy-ACC at Def-market-Gen
'Ali saw a boy at the market.'

(40)

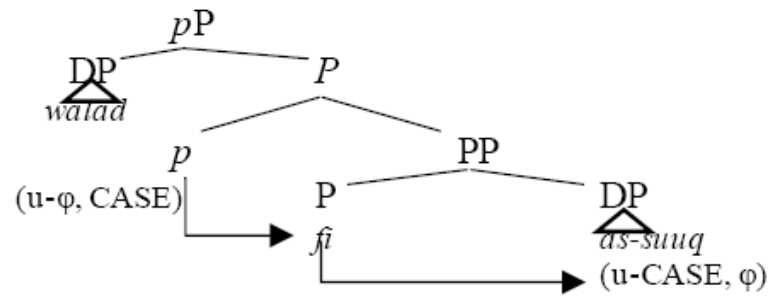

Concretely, the derivation within phasal $p \mathrm{P}$ proceeds when lexical $\mathrm{P} f i$ 'in' merges with its complement DP as-suuq 'def-market'. Once phasal $P$ enters the derivation, and under the FI model of Agree, it transfers its features to lexical P, and a $p$-P probe is formed. The $p$-P probe probes its domain for Goals and enters into Agree relation with the complement DP as-suuq. Agree between $p$-P and this DP results in valuation for the unvalued $\varphi$-features on the probe, and a similar valuation for the $u$ Case feature on the DP and Genitive Case value appears on the DP.

The derivation above the $p \mathrm{P}$ phase continues when the lexical head $\mathrm{V}$ enters the derivation and merges with $p \mathrm{P}$ phase as its complement. The phase head $v$ transfers its unvalued phi-features $(u \varphi)$ and valued CASE (i.e., Accusative) features to the lexical V head, and a $v$-V probe is formed. This probe searches for a possible Goal and probes the DP in spec $p \mathrm{P}$, thus valuing its $u$ CASE (i.e., Acc) and receiving valuation for its $(u \varphi)$ feature. The same Probe-Goal process occurs in the CP phasal level, and the subject DP (i.e., Ali) receives Nom Case value and the unvalued set of $\varphi$-features on the $\mathrm{C}-\mathrm{T}$ probe is valued, and the derivation converges.

$(41)$

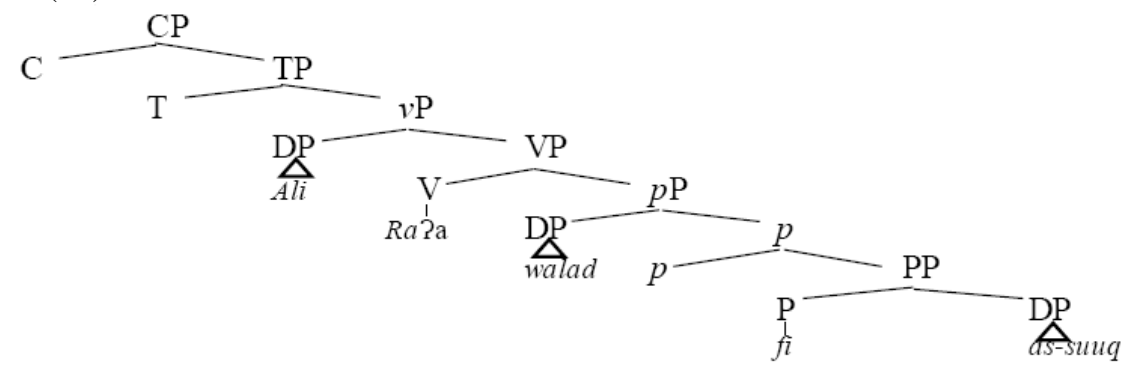

\section{CONCLUSION}

This paper has shown that PPs in MSA can be analyzed as phasal (i.e., $p \mathrm{P}$ ). Based on the FI model of Agree, a $p$-P probe is formed within a PP when phasal $p$ head transfers its unvalued ( $\varphi$-features) and valued Case feature (with a Genitive value) to lexical P. It has also been shown that the Genitive Case value on the DP complement for Ps in MSA is the outcome of an Agree relation between the $p$-P probe and its complement. Being phasal, $p$ can have a specifier which can host a DP (e.g., a complement for a higher probe).

\section{REFERENCES}

[1] Algryani, A. (2019). The syntax of sluicing in Omani Arabic. International Journal of English Linguistics, Vol. 9(6), $337-346$.

[2] Alhawary, M. (2016). Arabic grammar in context. New York: Routledge.

[3] Al-Marrani, Y. (2009). A comparative and contrastive study of preposition in Arabic and English. Language in India, 9, 47-68. Retrieved June 20, 2021, from http://www.languageinindia.com/july2009/almarranicontrast.pdf

[4] Baker, M. (2003). Lexical categories: Verbs, nouns, and adjectives (Cambridge studies in linguistics), 102. Cambridge University Press, Cambridge.

[5] Biber, D., Johansson, S., Leech, G., Conrad, S., \& Finegan, E. (1999). Longman grammar of spoken and written English. Harlow: Pearson Education Limited.

[6] Bittner, M., \& Hale, K. (1996). Ergativity: Towards a theory of a heterogeneous class. Linguistic Inquiry, 27, 531-604. 
[7] Brattico, P. (2012). Structural case assignment and phi-agreement in Finnish. SKY Journal of Linguistics, 25, 29-59.

[8] Carnie, A. (2008). Constituent structure (Oxford surveys in Syntax and Morphology 5). Oxford: Oxford University Press.

[9] Carter, R., \& McCarthy, M. (2006). Cambridge grammar of English: A comprehensive guide: Spoken and written English grammar and usage. Cambridge, UK: CUP.

[10] Chanturidze, M., Carrolla, R., \& Ruigendijk, E. (2019). Prepositions as a hybrid between lexical and functional category: Evidence from an ERP study on German sentence processing. In Journal of Neurolinguistics, 52, (pp. 1-18).

[11] Chomsky, N. (2005). Three factors in language design. Linguistic Inquiry, 36(1), 1-22.

[12] Chomsky, N. (2008). On phases. In R. Freidin, C. P. Otero, \& M. L. Zubizarreta (Eds.), Foundational issues in linguistic theory: Essays in honor of Jean-Roger Vergnaud (pp. 133-166). Cambridge, MA: The MIT Press.

[13] Croft, W. (1991). Syntactic categories and grammatical relations. Chicago: University of Chicago Press.

[14] Dikken, M. den. (1995). Particles: On the syntax of verb-particle, triadic, and causative constructions. Oxford: Oxford University Press.

[15] Dikken, M. den. (2010). On the functional structure of locative and directional PPs. In G. Cinque, \& L. Rizzi (Eds.), The cartography of syntactic structures, 6 (pp. 74-126). Oxford: Oxford University Press.

[16] Downing, A. \& Locke, P. (2006). English grammar: A university course $\left(2^{\text {nd }}\right.$ ed.). Abingdon \& New York: Routledge.

[17] Frank, M. (1972). Modern English. New Jersey: Prentice Hall Inc.

[18] Grimshaw, J. (1991). Extended projection. Unpublished manuscript, Brandeis University, Waltham, Mass. (Also appeared in J. Grimshaw (2005), Words and Structure, Stanford: CSLI).

[19] Hale, K., \& Keyser, S. J. (1993). On argument structure and the lexical expression of syntactic relations. In K. Hale, \& S. J. Keyser (Eds.), The view from building 20: Essays in linguistics in honor of Sylvain Bomberger (pp. 53-109). Cambridge, MA: The MIT Press.

[20] Halliday, M., \& Matthiessen, C. (2014). Halliday's introduction to functional grammar (4th ed). London: Routledge.

[21] Hamdallah, R., \& Tushyeh, H. (1993). A contrastive analysis of selected English and Arabic prepositions with pedagogical implications. PSiCL, 28, 181-190.

[22] Hasan, A. (1976). An-nahu al-waafi [The complete syntax]. Cairo, Egypt: Daar AlmaGaarif.

[23] Hoekstra, T. (1988). Small clause results. Lingua, 74, 101-139.

[24] Jackendoff, R. (1977). X-bar syntax. Cambridge, Mass.: MIT Press.

[25] Jackendoff, R. (1990). Semantic structures. Cambridge: The MIT Press.

[26] Keizer, E. (2008). English prepositions in functional discourse grammar. Functions of Language, 15(2), 216-256.

[27] Lamontagne, G., \& Travis, L. (1987). The Case Filter and the ECP. McGill Working Papers in Linguistics, 3(2), 51-75.

[28] Macková, L. (2012). A contrastive analysis of the prepositions To and Into. (Master thesis, Masaryk University, Brno, Czech Republic). Retrieved May, 12, 2021, from https://is.muni.cz/th/261212/ff_m/MA_thesis.pdf

[29] O' Grady, W. (1996). Syntax: The analysis of sentence structure. In W. O'Grady, M. Dobrovolsky, \& F. Katamba (Eds.), Contemporary linguistics: An introduction (pp. 181-244). New York: Longman.

[30] Ouhalla, J. (1994). Introducing transformational grammar: From rules to principles and parameters. London: Edward Arnold.

[31] Puigdollers, C. (2013). Lexicalization by phase: The role of prepositions in argument structure and its cross-linguistic variation. (Doctoral dissertation, Universitat Autonoma de Barcelona). Retrieved June 14, 2021, from https://www.tdx.cat/bitstream/handle/10803/120181/crp1de1.pdf?sequence=1

[32] Quirk, R., Greenbaum, S., Leech, G., \& Svartvik, J. (1985). A comprehensive grammar of the English language. London: Longman.

[33] Radford, A. (2004). Minimalist Syntax: Exploring the structure of English. Cambridge, England: Cambridge University Press.

[34] Rauh, G. (2002). Prepositions, features, and projections. In H. Cuyckens, \& G. Radden (Eds.), Perspectives on prepositions (323). Tübingen: Niemeyer.

[35] Richards, M. (2011). Deriving the edge: What's in a phase? Syntax 14(1), 74-95.

[36] Rooryck, J. (1996). Prepositions and minimalist case marking. In H. Thrainsson, S. D. Epstein, \& S. Peter (Eds.), Studies in Comparative Germanic Syntax II, (226-256). Amsterdam: Kluwer.

[37] Saeed, S. (2014). The Syntax and Semantics of Arabic Spatial Prepositions. Newcastle and Northumbria Working Papers in Linguistics, 20, 44-66.

[38] Saleh, Y. (2015). Contrastive analysis of prepositional phrases and noun phrases in the English and Arabic languages. Journal of Tikrit University for the Humanities, 22(9), 368-414.

[39] Sibaweihi, A. (n.d.). Al-kitaab [The book]. A. Haruun (Ed.). Retrieved March 20, 2021, from http://www.almeshkat.net/books/open.php?cat=16\&book=484

[40] Stowell, T. (1983).Subjects across categories. The Linguistic Review, 2, 285-312.

[41] Tseng, J. (2000). The Representation and Selection of Prepositions. (Doctoral dissertation, Edinburgh University). Retrieved July 14, 2021, from https://tel.archives-ouvertes.fr/halshs-00004845/document

[42] Van Valin, R. (2004). An Introduction to Syntax. Cambridge, England: Cambridge University Press.

[43] Venonius, P. (2010). Spatial P in English. In G. Cinque \& L. Rizzi (Eds.). The cartography of syntactic structures, 6, (pp. 127160). Oxford: Oxford University Press.

[44] Wishon, G., \& Burks, J. (1980). Let's Write English. New York: American Book Company.

[45] Zewi, T. (2012). Prepositional phrases as subjects in several Semitic languages. In Hasselbach, R. \& Pat-El, N. (Eds), Language and Nature: Papers Presented to John Huehnergard on the Occasion of His 60th Birthday (pp. 465-476). Chicago: The Oriental Institute.

\footnotetext{
Ahmad Assiri was born in Abha, Saudi Arabia on January 2, 1977. In 2011, Ahmad Assiri received his PhD in linguistics (syntax) from Memorial University of Newfoundland, St. John's, NL, Canada. In 2003, Ahmad Assiri obtained his MA degree - in linguistics-
} 
in 2003 from West Virginia University, Morgantown, WV, USA. In 2000, Ahmad Assiri graduated with a BA degree - in Englishfrom King Khalid University (KKU), Abha, Saudi Arabia.

Since September 2019, Ahmad Assiri has been the Vice-Dean for the Deanship of Graduate Studies at KKU. He has also worked as the Senior Supervisor for Curricula \& Plans Unit, Vice-Rectorate for Educational \& Academic Affairs, KKU between September 2017 and August 2019. He has also worked as the Vice-Dean for the Faculty of Languages and Translation, KKU between December 2012 and November 2015.

He has published some articles such as:

Assiri, Ahmad (2014). Sociolinguistic Variation in Rijaal Almaৎ, Saudi Arabia: A Dialectological Study. King Khalid University Journal of Humanities, 23, (2), 74-122.

Assiri, Ahmad (2015). Word-Final Consonant Clusters in Three Dialects of Arabic. King Khalid University Journal of Humanities, $24,(2), 11-51$.

Assiri, Ahmad (2021). Gapping in Modern Standard Arabic: An Agree-Based Analysis. Umm Al-Qura University Journal of Languages and Literatures, 27, 479-513.

His research interest is in Syntactic theory (Arabic syntax), Government Phonology, and Sociolinguistics.

Dr. Assiri received a scholarship from KKU to pursue his MA degree in 2001. In 2005, he received another scholarship from KKU to pursue his PhD. Dr. Assiri is the recipient of Prince Bandar bin Sultan's Award for excellent academic achievement, Saudi Cultural Bureau, Washington, DC in 2004. 